This item was submitted to Loughborough's Research Repository by the author.

Items in Figshare are protected by copyright, with all rights reserved, unless otherwise indicated.

\title{
Numerical studies of premixed hydrogen/air flames in a small-scale combustion chamber with varied area blockage ratio
}

PLEASE CITE THE PUBLISHED VERSION

https://doi.org/10.1016/j.ijhydene.2020.03.204

PUBLISHER

Elsevier

VERSION

AM (Accepted Manuscript)

\section{PUBLISHER STATEMENT}

This paper was accepted for publication in the journal International Journal of Hydrogen Energy and the definitive published version is available at https://doi.org/10.1016/j.ijhydene.2020.03.204.

\section{LICENCE}

CC BY-NC-ND 4.0

\section{REPOSITORY RECORD}

Elshimy, Mohamed, Salah Ibrahim, and Weeratunge Malalasekera. 2020. "Numerical Studies of Premixed Hydrogen/air Flames in a Small-scale Combustion Chamber with Varied Area Blockage Ratio". Loughborough University. https://hdl.handle.net/2134/12037539.v1. 


\title{
Numerical studies of premixed hydrogen/air flames in a small-scale combustion chamber with varied area blockage ratio
}

\author{
M. Elshimy ${ }^{a,}$, , S. Ibrahim ${ }^{a}$ and W. Malalasekera ${ }^{b}$
}

a Department of Aeronautical and Automotive Engineering, Loughborough University, Loughborough, LE11 3TU, UK

${ }^{b}$ Wolfson School of Mechanical, Electrical and Manufacturing Engineering, Loughborough University, Loughborough, LE11 3TU, UK

\section{Abstract}

The increasing use of hydrogen as a renewable source of energy underlines the need to be able to assess the safety risks involved in the event of an accidental explosion. This paper presents numerical studies for hydrogen/air propagating flames at an equivalence ratio of 0.7 in a laboratory-scale combustion chamber equipped with turbulence generating baffles and a solid square cross section obstruction. The large eddy simulation (LES) modelling technique is used with an inhouse computational fluid dynamics (CFD) model for compressible flows to study the flow turbulence and the flame propagation characteristics. The study is carried out using four different baffle arrangements and two different solid obstructions with area blockage ratios of 0.24 and 0.5 . Results for the generated peak overpressure and the timing at which it occurs following ignition are considered as the primary safety factors. The time histories of the flame speed and position relative to the ignition source are validated against published experimental data. Good agreement is obtained between numerical results and experimental data which enables further predictions where measurements are limited in the study of vented hydrogen explosions. It was concluded that adding successive baffles and increasing the area blockage ratio escalates the maximum rate at which pressure rises and raises the generated peak explosion overpressure.

\section{Introduction}

Hydrogen $\left(\mathrm{H}_{2}\right)$ has the potential to be used as a replacement fuel due to its renewability and relatively high energy density when compared to alternative hydrocarbons [1,2]. There is an opportunity in using hydrogen as a fuel for road vehicles and this has been proven with the development and subsequent release of hydrogen fuel cell electric vehicles to the public [3-5]. Attempts are also being made to develop a further understanding of hydrogen-fuelled internal combustion engines [6]. Hydrogen is also being considered as zero-carbon alternative to hydrocarbons for domestic or commercial heating [7]. With supporting hydrogen stations currently under construction, research is carried out to ensure sufficient engineering controls are in place for both normal and emergency operations $[8,9]$. As a result, it is necessary to consider the safety implications in the transport, storage and use of hydrogen as a fuel $[3,4,10,11]$. Hydrogen's relatively low density and wide range of flammability denotes that it mixes rapidly with surrounding air if released into the atmosphere, following which it is very prone to accidental explosions [12]. This is

* Corresponding author.

E-mail address: m.a.a.a.elshimy@lboro.ac.uk 
particularly dangerous in a partially-confined space as has been confirmed by several lab-scale studies of hydrogen deflagration [13-15]. Experimental studies published for several years have confirmed that hydrogen produces significantly higher explosion overpressure at much higher propagating flame speeds when compared to methane $\left(\mathrm{CH}_{4}\right)$ and propane $\left(\mathrm{C}_{3} \mathrm{H}_{8}\right)[16,17]$. These characteristics along with previous instances of accidents such as the Fukushima Daiichi nuclear disaster $[18,19]$ highlight the importance of further understanding hydrogen combustion. The study presented in this paper uses the LES modelling technique to investigate the flame structure of lean hydrogen flames as they propagate through baffles and past a solid obstruction out of a vented chamber. The numerical results obtained are validated against experimental data obtained by Masri et al. [16]. The resultant peak explosion overpressure depends on various parameters such as the fuel/air equivalence ratio, the spacing between obstacles and their distance from the ignition source [20-23]. These obstacles act as turbulence generators ahead of the flame as it propagates through the baffles and past the solid obstruction [20,24]. As a result, a suitable numerical model would need to be able to predict how the obstacles and turbulence levels within the chamber influence the flame structure [20,21,25]. Large and small scale experiments have been previously carried out for hydrogen/air explosions and compared them to substitute hydrocarbons [16,17,26-29]. These experiments can be used to validate numerical models for further use.

Numerical modelling has proven to be an outstanding alternative in various industries including fluid dynamics, aeronautical and automotive, considering problems with complex non-reacting flows. As for turbulent reacting flows, there remain unresolved issues where further research is required. The accomplishments of numerical modelling in applications with non-reacting flows mean that there is an increasing use in the numerical modelling of turbulent combustion. Generally, the main computational modelling techniques are Direct Numerical Simulations (DNS), Reynolds Averaged Navier-Stokes (RANS) and Large Eddy Simulations (LES).

Previous research has successfully carried out numerical simulation for several applications of complex reacting flows [30-34]. Further, numerical results obtained through computational modelling convey how the flow reacts to various obstacles and obstructions in a semi-confined space [35-39]. The numerical approach still relies on an adequate turbulence and combustion model in order to accurately perform numerical analysis for a hydrogen explosion. A cost and time effective approach needs to be utilised depending on the application and computational resources available in order to produce adequate results within an acceptable amount of time [40]. The DNS technique is not typically applied due to relatively high computational expense when compared to suitable alternatives. The RANS technique has been accepted due to its satisfactory results for large scale applications [34,41-43]. On the other hand, the LES technique for turbulent flows has been used to numerically study vented explosions in lab-scale applications [1115,27-29,34-42]. One of the key factors to consider for the LES technique is an appropriate sub-grid-scale (SGS) combustion model which is capable of providing results across a range of mixtures and flow conditions [53-55]. Flame surface density (FSD) based models have been applied for several test cases using turbulent premixed combustion. The FSD approach models the reaction rate as a 
function of a defined filter width and a reaction progress variable. Previous studies have shown the importance of an appropriate FSD based SGS analysis using LES modelling [56-59]. In order to account for the unresolved part of the SGS reaction rate a dynamic flame surface density (DFSD) model obtains data from the resolved flame front as it propagates. This paper focuses on further validating the DFSD model for a lean hydrogen/air mixture at an equivalence ratio of 0.7 applied with two different area blockage ratios. Four different turbulence generating baffle configurations are used with smaller and larger area blockage ratios to validate the model and investigate numerical results where experimental data is available $[16,17]$. Further numerical predictions are made where experiments were limited.

\section{Experimental setup}

Experimental data is obtained using the laboratory scale combustion chamber developed at the University of Sydney, Australia $[16,17,60]$. The chamber measures $50 \times 50 \times 250 \mathrm{~mm}$ (5:1 aspect ratio) with a total volume of 0.625 litres. A schematic of the chamber is shown in Fig.1. The chamber is equipped with three removable baffles with five $4 \mathrm{~mm}$ wide and $3 \mathrm{~mm}$ thick strips separated by $5 \mathrm{~mm}$ gaps which provide an area blockage ratio (ABR) of $40 \%$. Each baffle provides a volume blockage ratio (VBR) of $0.48 \%$ and is placed at $19 \mathrm{~mm}, 49 \mathrm{~mm}$ and $79 \mathrm{~mm}$

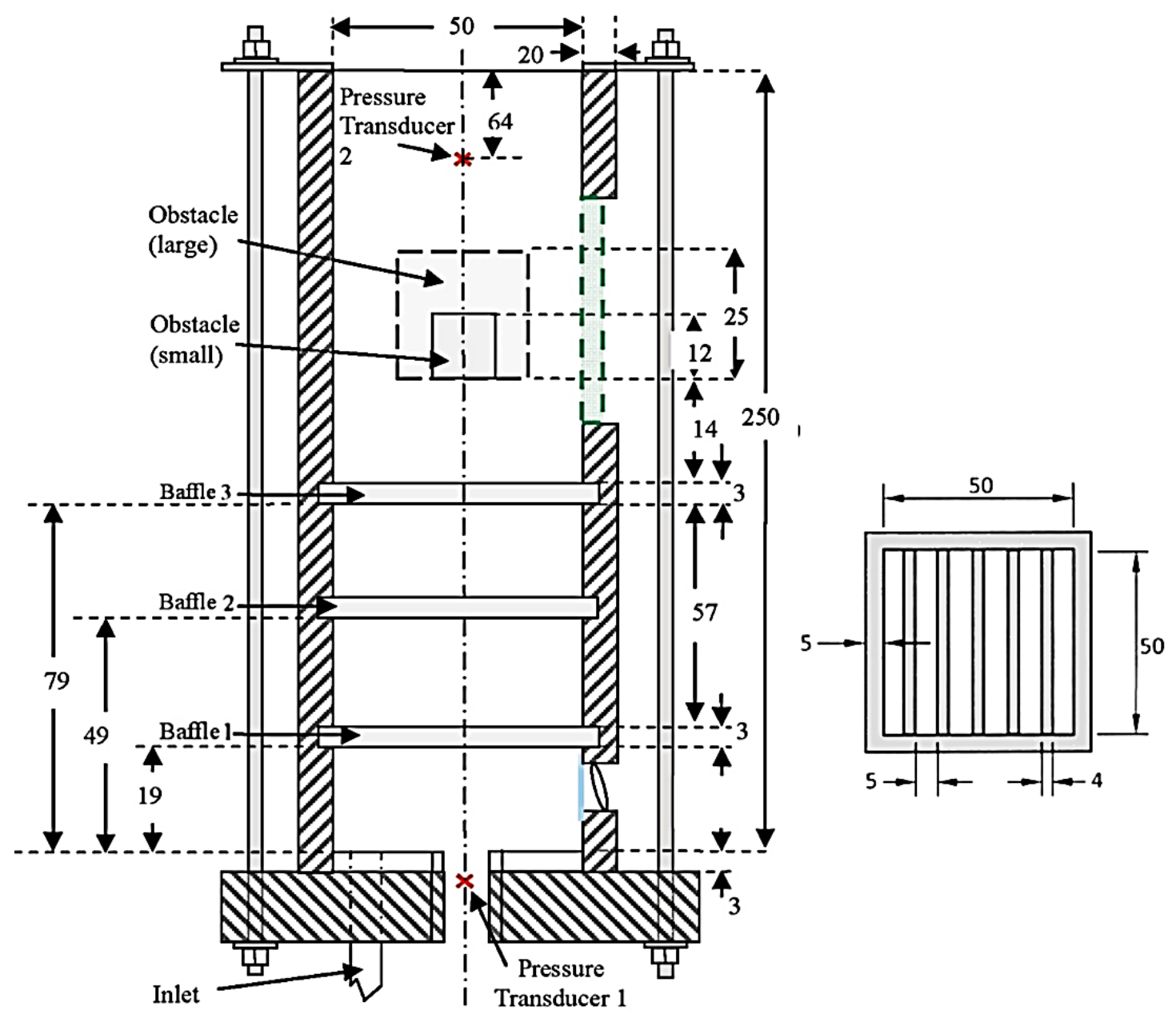

Fig. 1 - Schematic of the combustion chamber (left) and removable baffle (right) (all dimensions in $\mathrm{mm}$, not to scale). 
downstream from the ignition source at the base of the chamber. The solid obstacle is placed at $96 \mathrm{~mm}$ from the base of the chamber. Two different central obstacles are used. The small solid obstacle has a square cross-section of $12 \times 12 \mathrm{~mm}$ resulting in an ABR of $24 \%$ and a VBR of $1.152 \%$. The large solid obstacle has a square crosssection of $25 \times 25 \mathrm{~mm}$ resulting in an ABR of $50 \%$ and a VBR of $5 \%$.

The lean hydrogen/air mixture enters the chamber through a non-return valve at atmospheric pressure and is allowed to settle before ignition is activated. One second before ignition, a hinged flap at the top of the chamber is opened and remains open which allows for venting of the explosion. The mixture is then ignited by an Nd: YAG laser which focuses an infrared output at $2 \mathrm{~mm}$ above the base of the chamber defining the start time for the experiment. Pressure readings are taken using two Keller type PR21-SR piezo-electric pressure transducers at a rate of 25 $\mathrm{kHz}$. One of the transducers is placed in the base of the chamber and the other is placed at $64 \mathrm{~mm}$ from the top in the wall of the chamber. The evolution of the reaction zones is captured with high-speed laser-induced fluorescence from $\mathrm{OH}$ $(\mathrm{LIF}-\mathrm{OH})$ at a rate of $5 \mathrm{kHz}$. Four different baffle configurations combined with the small and large obstacle for a total of 8 configurations are investigated in this study and these configurations are shown in Fig. 2. The configurations are named based on the arrangement of baffles and the size of the obstacle used. For example, configuration BBBS uses baffle 1, baffle 2 and baffle 3 with a small central obstacle, whereas configuration $\mathrm{OBOL}$ uses only Baffle 2 and a large central obstacle. The experimental data shown for each configuration in this paper is an average acquired from approximately 50 experiments.

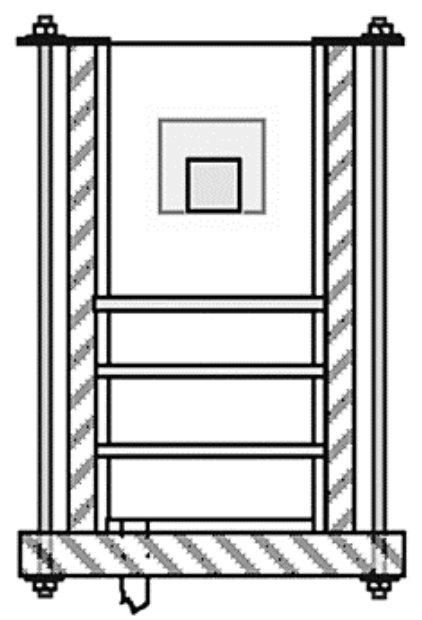

BBB

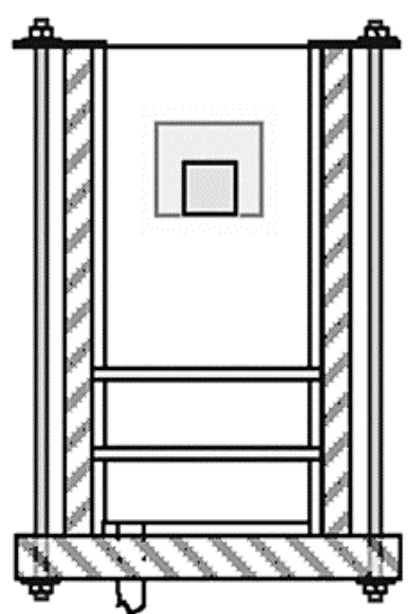

BBO

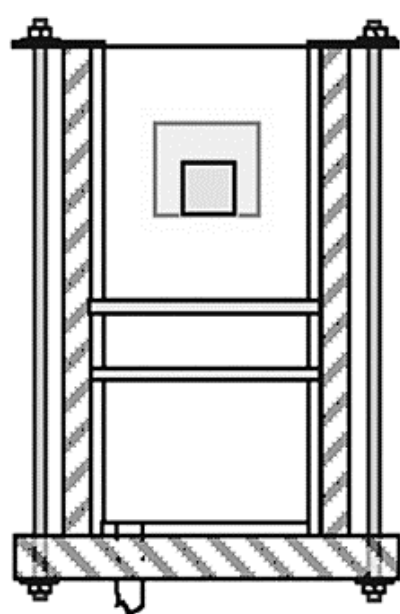

OBB

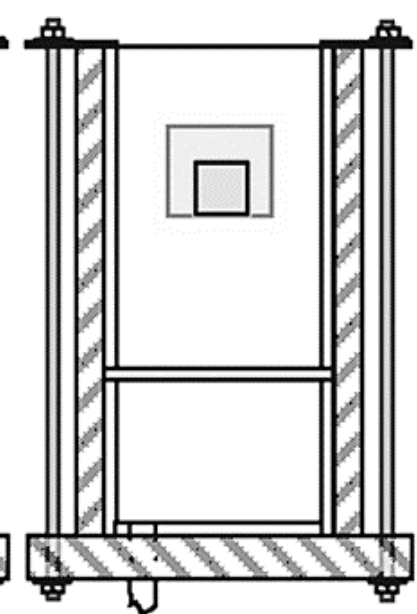

OBO

Fig. 2 - The 4 different baffle configurations shown which can be used with the Large (L) or Small (S) obstacles.

\section{Experimental limitations}

Experiments carried out using LPG (Liquified Petroleum Gas) and CNG (Compressed Natural Gas) successfully obtained overpressure and flame position data for various configurations with the large and small obstacle $[16,17,60]$. However, experiments carried out by AlHarbi [60] using lean hydrogen/air mixtures concluded that experimental equipment is limited and would need to be more advanced in order to obtain flame position data for hydrogen deflagration when using 
the large obstacle. Experimental images could only be obtained for configuration OBOL, which uses a single baffle in the middle of the chamber and the large solid obstacle, using a solid obstacle with an ABR of $50 \%$ as a result of the excessive propagating flame speed, even when using a lean hydrogen/air equivalence ratio. This means that although images were captured for experiments when using configuration $\mathrm{OBOL}$ there is a visible lack of detail due to limitations in the experimental equipment which would need to be more advanced. This lack of detail when compared to the smaller ABR is reflected in the experimental data points for the flame position and speed data.

As a result, numerical results for the flame position and speed provide a prediction where experimental equipment was limited. As for the overpressure, data is available for multiple configurations using the larger ABR as it is within the limit of the piezoelectric pressure transducers. This is only achieved by using an equivalence ratio of $\Phi=0.7$ for the mixture to keep within the $100 \mathrm{kPa}(1000 \mathrm{mbar})$ limit of the pressure transducers as explained by Masri et al. [16]. Combining a higher equivalence ratio with the larger ABR would result in excessive pressures beyond the limit of the transducers.

\section{Numerical setup}

Numerical simulations are governed by conservation equations for mass, momentum and energy. The reaction progress variable $\tilde{c}$ conveys the chemical state of a fuel/air mixture. Modelling the reaction rate for turbulent premixed flames can be difficult due to the complex interaction between the levels of turbulence as well as the thermodynamic, chemical states. Nevertheless, Neglecting Zeldovich instability, using a unity Lewis number and assuming a single step irreversible chemical reaction between reactants and products reduces the complexity of the system. More of the numerical model is detailed elsewhere [48].

The reaction progress variable $\tilde{c}$ is given by:

$$
\tilde{\mathrm{c}}=1-\frac{m_{f}}{m_{f}^{0}}
$$

where, $m_{f}$ is the local fuel mass fraction and $m_{f}^{0}$ is the fuel mass fraction unburned in the mixture. For the reaction progress variable, $\tilde{c}=1$ is a fully burned mixture and $\tilde{c}=$ 0 is an unburned mixture. The general form of the Favre-filtered transport equation for the reaction progress variable $\tilde{c}$ is given by:

$$
\frac{\partial \bar{\rho} \tilde{\mathrm{c}}}{\partial \mathrm{t}}+\frac{\partial}{\partial \mathrm{x}_{\mathrm{i}}}\left(\bar{\rho} \widetilde{\mathrm{u}_{1}} \widetilde{\mathrm{c}}\right)=-\frac{\partial}{\partial \mathrm{x}_{\mathrm{i}}}\left(\bar{\rho} \widetilde{\mathrm{u}}_{1} \widetilde{\mathrm{c}}-\bar{\rho} \widetilde{\mathrm{u}_{1}} \widetilde{\mathrm{c}}\right)+\overline{\frac{\partial}{\partial \mathrm{x}_{1}}\left(\rho \mathrm{D} \frac{\partial \widetilde{\mathrm{c}}}{\partial \mathrm{x}_{1}}\right)}+\overline{\dot{\omega}_{\mathrm{c}}}
$$

Where $\overline{\omega_{\mathrm{c}}}$ is the filtered source term and is given using the flame surface density (FSD) concept as:

$$
\overline{\omega_{\mathrm{c}}}=\rho_{\mathrm{u}} \mathrm{S}_{\mathrm{L}}^{0} \Sigma
$$

where $\rho_{\mathrm{u}}$ is the unburned mixture density and $\mathrm{S}_{\mathrm{L}}^{0}$ is the un-strained laminar burning velocity. The sub-grid scale flame surface density $\sum$ is given by:

$$
\Sigma=4 \sqrt{\frac{6}{\pi}} \Xi_{\Delta} \frac{\widetilde{c}(1-\tilde{c})}{\Delta}
$$


where $\Delta$ is the combustion filter width and $\Xi_{\Delta}$ is the sub-grid scale wrinkling factor. Substituting equations (3) and (4) into the $\tilde{c}$ equation (2) gives [56,61]:

$$
\frac{\partial \bar{\rho} \tilde{\mathrm{c}}}{\partial \mathrm{t}}+\frac{\partial}{\partial \mathrm{x}_{\mathrm{i}}}\left(\bar{\rho} \widetilde{\mathrm{u}_{1}} \tilde{\mathrm{c}}\right)=\frac{\partial}{\partial \mathrm{x}_{\mathrm{i}}}\left(\frac{\rho_{\mathrm{u}} \Xi_{\Delta} S_{\mathrm{L}}^{0} \Delta}{16 \sqrt{6 / \pi}} \frac{\partial \widetilde{\mathrm{c}}}{\partial \mathrm{x}_{\mathrm{i}}}\right)+4 \rho_{\mathrm{u}} S_{\mathrm{L}}^{0} \sqrt{\frac{6}{\pi}} \Xi_{\Delta} \frac{\tilde{\mathrm{c}}(1-\tilde{\mathrm{c}})}{\Delta}
$$

Previous research suggests that the combustion filter width $\Delta$ should be greater than the mesh size $\Delta_{x}$ enabling the filtered progress variable gradients to be well resolved using an LES grid [59]. In this study the filter width used is 6 times the mesh size $(\Delta$ $=6 \Delta x)$. The laminar burning velocity is set to $1.25 \mathrm{~m} / \mathrm{s}$ and the thermal flame thickness is set a $0.12 \mathrm{~mm}$ for a hydrogen/air mixture at an equivalence ratio of 0.7 $[62,63]$.

\section{Computational setup}

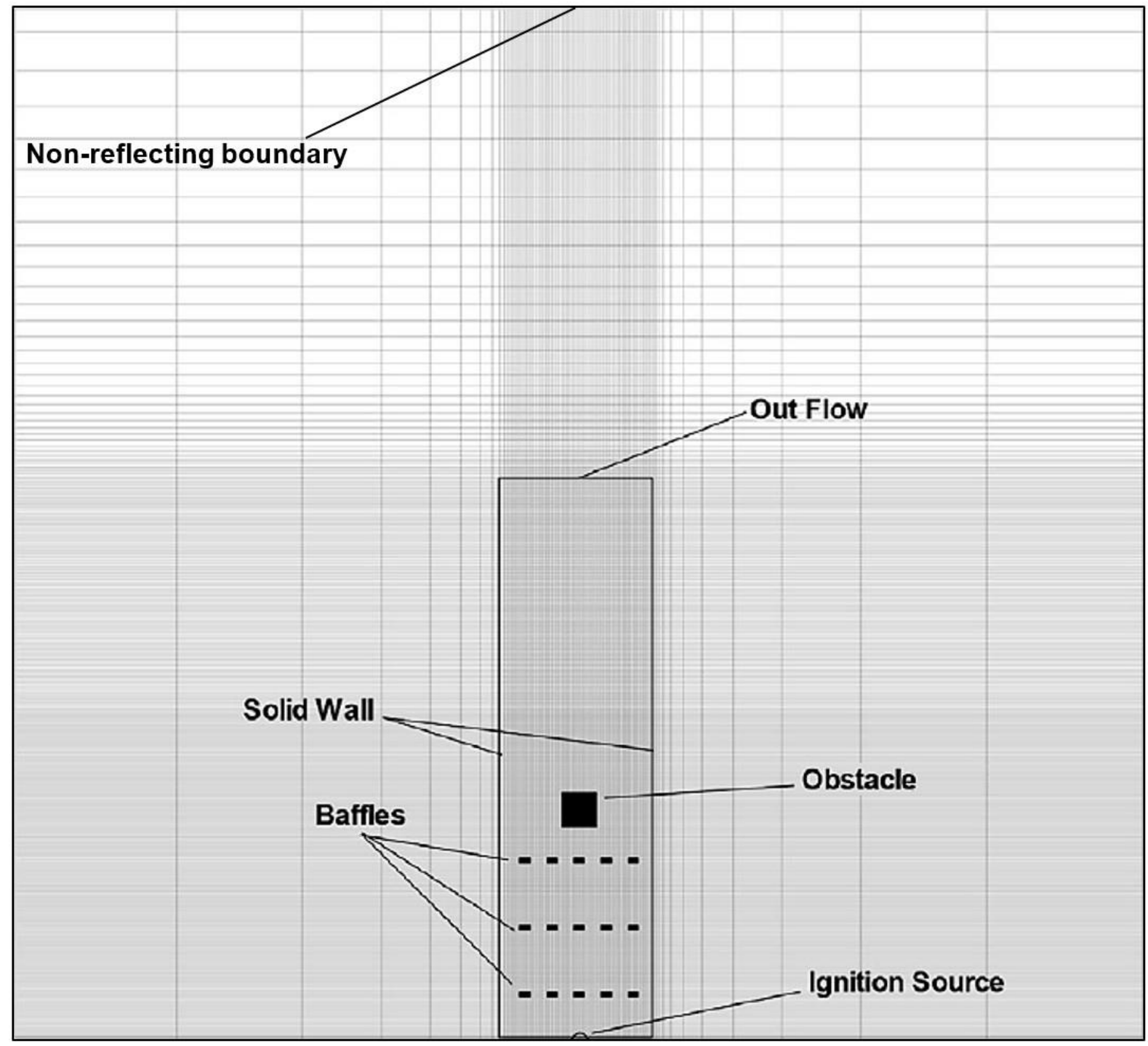

Fig. 3 - Computational domain showing grid resolution, combustion chamber, baffles and the small solid obstacle.

Numerical analysis using LES for hydrogen explosions is carried out using an inhouse code known as PUFFIN [64]. The code uses the finite volume method on a 
Cartesian grid to solve for equations of mass, momentum and scalar equations for compressible flow. The computational domain measures $50 \times 50 \times 250 \mathrm{~mm}$ for the chamber whereas the complete domain measures $325 \times 325 \times 500 \mathrm{~mm}$ with nonreflecting boundary conditions for the far field boundaries as shown in Figure 2. The solid walls of the chamber have adiabatic and no-slip boundary conditions. The shear stress at the wall is calculated using the $1 / 7^{\text {th }}$ power law wall function developed by Werner and Wengle [65]. More details on the boundary conditions, chemical model and reaction mechanism can be found elsewhere [64]. Following a grid sensitivity study a 2.7 million $(90 \times 90 \times 336)$ cell grid was selected for configurations using both the small and large obstacles. Figure 3 shows the mesh refinement with the combustion chamber, baffles and solid obstacle. Ignition is provided by initialising a burned flame kernel which sets a defined number of cells to have a reaction progress variable of 0.5 . The kernel is hemispherical in shape with a $4 \mathrm{~mm}$ radius and it is located at the base of the chamber.

\section{Results and discussion}

The results convey the nature of flame obstacle interaction as well as the resultant overpressure produced due to the explosion in the chamber. Maximum overpressures, rates which pressures rise and transient flame speeds are obtained from LES and compared with experimental data.

Results will be used to compare between $\mathrm{H}_{2}$ and LPG, underlining the difference between the fuels and the difference in key combustion events and overpressuretime traces produced using an ABR of $25 \%$ when compared to an ABR of $50 \%$. The main focus is on the area blockage ratio effects due to increased solid obstacle size and the effect of baffle configuration.

\section{Effect of baffle configuration}

Overpressure time traces shown in shown in Fig. 4 compare the results obtained using LES with the data attained from experiments. Fig. 4 conveys the trend of pressure rise for the hydrogen explosions using different configurations and an ABR of $50 \%$ for both the numerical results and experimental data. Fig. 5 shows a comparison between the overpressure-time traces for the configurations using the large solid obstacle $(50 \% A B R)$ and the small solid obstacle (24\% ABR). Observing the results in Figure 4 conveys that the additional baffles increase the peak magnitude of overpressure produced. The additional baffles also increase the rate at which pressure rises after ignition is provided and reduces the amount of time required in order to reach the peak overpressure magnitude. Configuration OBOL in Fig. 4a uses only one central baffle and produces the lowest peak overpressure of $522 \mathrm{mbar}$ at $5.7 \mathrm{~ms}$. Utilising an additional baffle increases the turbulence intensity in the chamber and produces a higher peak overpressure in less time. This is shown in Fig. $4 \mathrm{~b}$ where configuration $\mathrm{BBBL}$ produces 669 mbar of overpressure at $4.79 \mathrm{~ms}$. Peak overpressure for configuration BB0L shown in Fig. 4c was found to be 806 mbar at $4.65 \mathrm{~ms}$. The maximum overpressure of $898 \mathrm{mbar}$ is achieved using configuration BBBL, which has all three baffles equipped, in the least amount of time at $4.46 \mathrm{~ms}$.

The maximum rate of pressure rise also increases when additional baffles are placed in the chamber. The experimental result for configuration BBBL is $337 \mathrm{MPa} / \mathrm{s}$ whereas LES produces max pressure gradient, dp/dt, of $302 \mathrm{MPa} / \mathrm{s}$ at $4.4 \mathrm{~ms}$. 
Configuration OBOL produces a maximum value for $\mathrm{dp} / \mathrm{dt}$ of $184 \mathrm{MPa} / \mathrm{s}$ experimentally, while numerical results found the maximum rate of pressure rise to be $176.79 \mathrm{MPa} / \mathrm{s}$ at $5.97 \mathrm{~ms}$. This is also consistent when comparing configurations using the small obstacle where configuration BB0S in Fig. 5b produced 467 mbar at $4.32 \mathrm{~ms}$ while configuration OBOS produced 324 mbar at $5.20 \mathrm{~ms}$. The rate of pressure rise also increases with the number of baffles where configuration OBBS reaches $\mathrm{dp} / \mathrm{dt} \max$ of $279 \mathrm{MPa} / \mathrm{s}$ whereas the maximum rate of pressure rise for

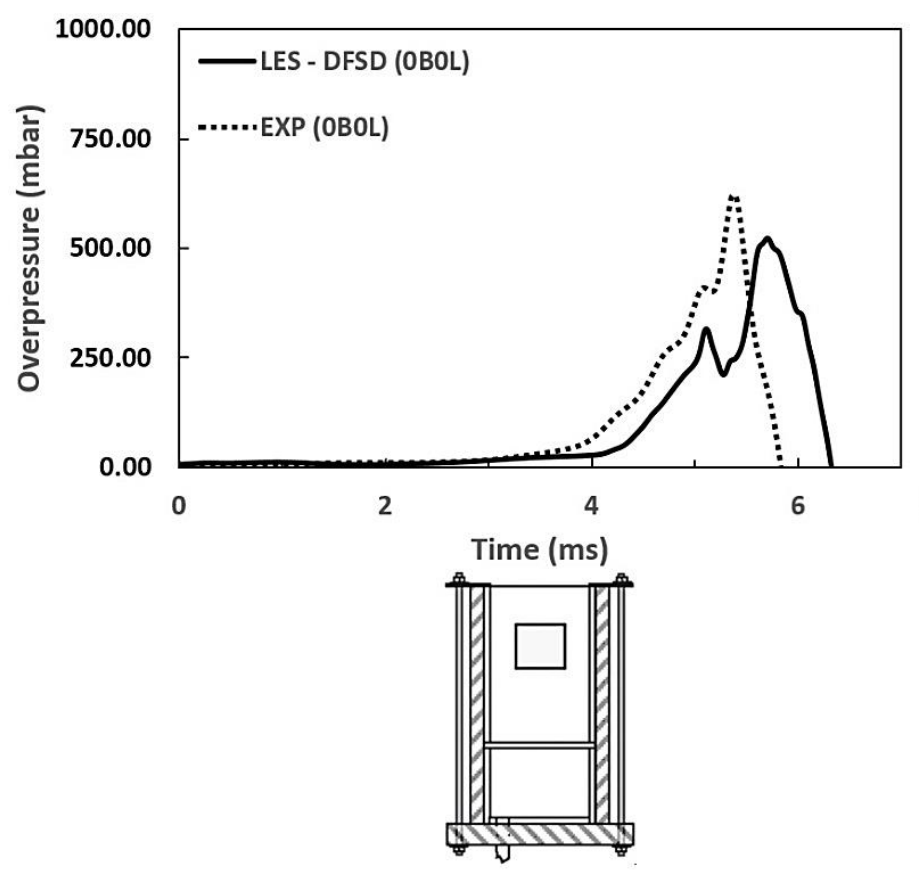

(a) Overpressure time-traces for configuration $\mathrm{OBOL}$.

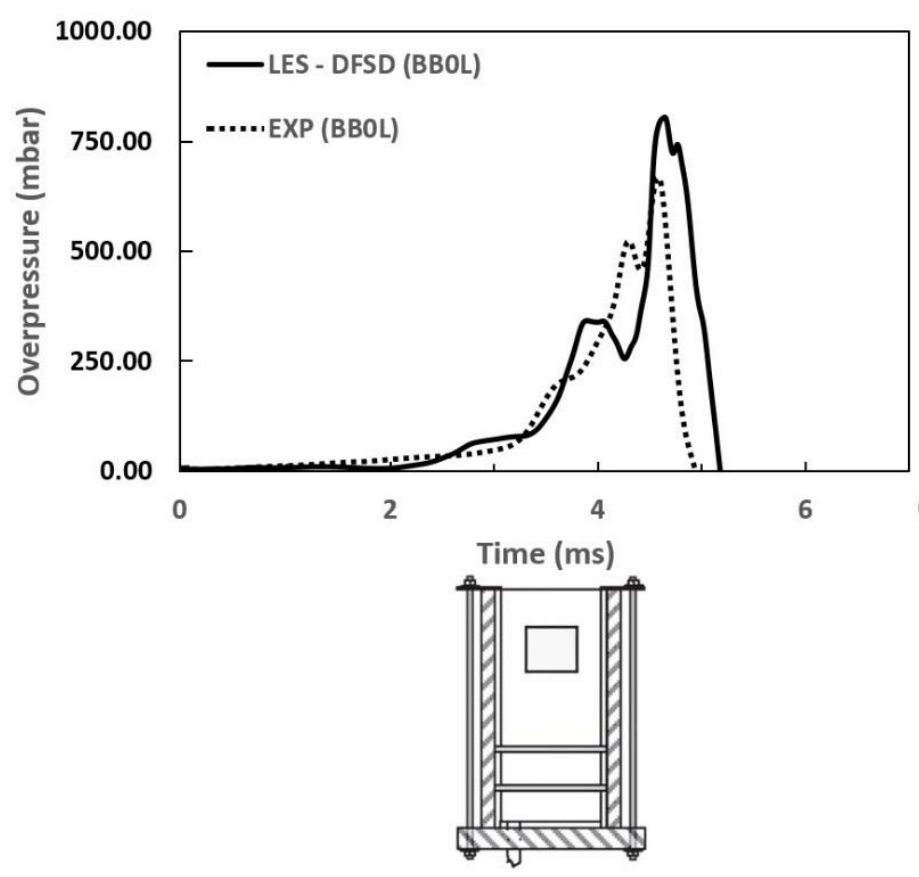

(c) Overpressure time-traces for configuration BBOL.

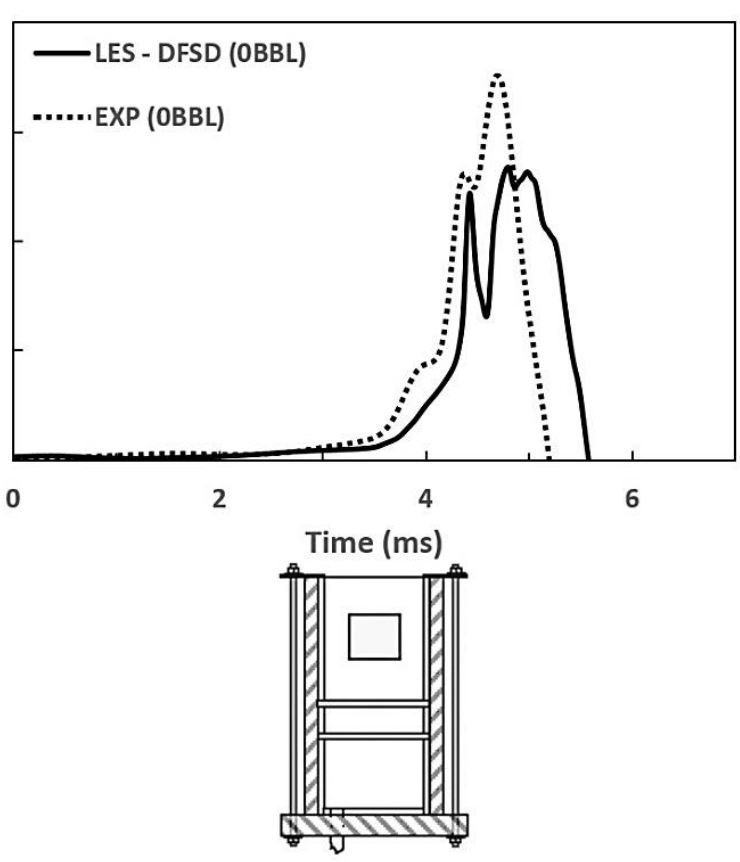

(b) Overpressure time-traces for configuration $\mathrm{OBBL}$.

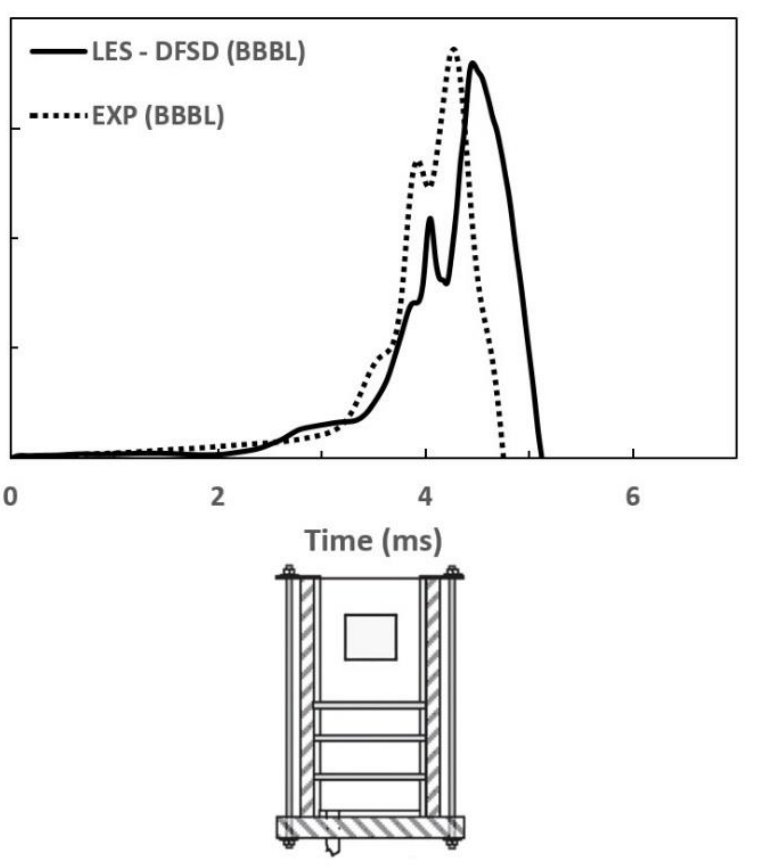

(d) Overpressure time-traces for configuration BBBL.

Fig. 4 - Overpressure-time traces for configurations using the large obstacle. 
configuration BBBS is $300 \mathrm{MPa} / \mathrm{s}$. The baffle configuration also affects the obstacle separation distance which when reduced, increases the combustion overpressure. It is also inferred that including successive baffles also decreases the obstacle separation distance. Figure 5 illustrates that configuration BB0S which has a distance of $47 \mathrm{~mm}$ between the second baffle and the obstacle produces a peak overpressure of 635.95 at $4.90 \mathrm{~ms}$. On the other hand, configuration OBBS which only has a gap of $17 \mathrm{~mm}$ between the final baffle and the small obstacle produced a lower peak overpressure of 466.72 at $4.32 \mathrm{~ms}$. Similar observations have been made in other experimental studies [66].

The rate at which pressure rises is also affected by the reduced separation distance. Configuration BB0S produced a peak rate of pressure rise of $110.85 \mathrm{MPa} / \mathrm{s}$ numerically whereas the experiment found that the maximum rate of pressure rise is $71.07 \mathrm{MPa} / \mathrm{s}$. The experiment using configuration 0BBS recorded a maximum rate of pressure rise of 274.22 where the LES-DFSD result found the maximum rate of pressure rise to be $300.32 \mathrm{MPa} / \mathrm{s}$. These pressure history curve results are consistent with the experimental data as shown in Fig. 4 and 5 , and is consistent with previously published numerical results [39].

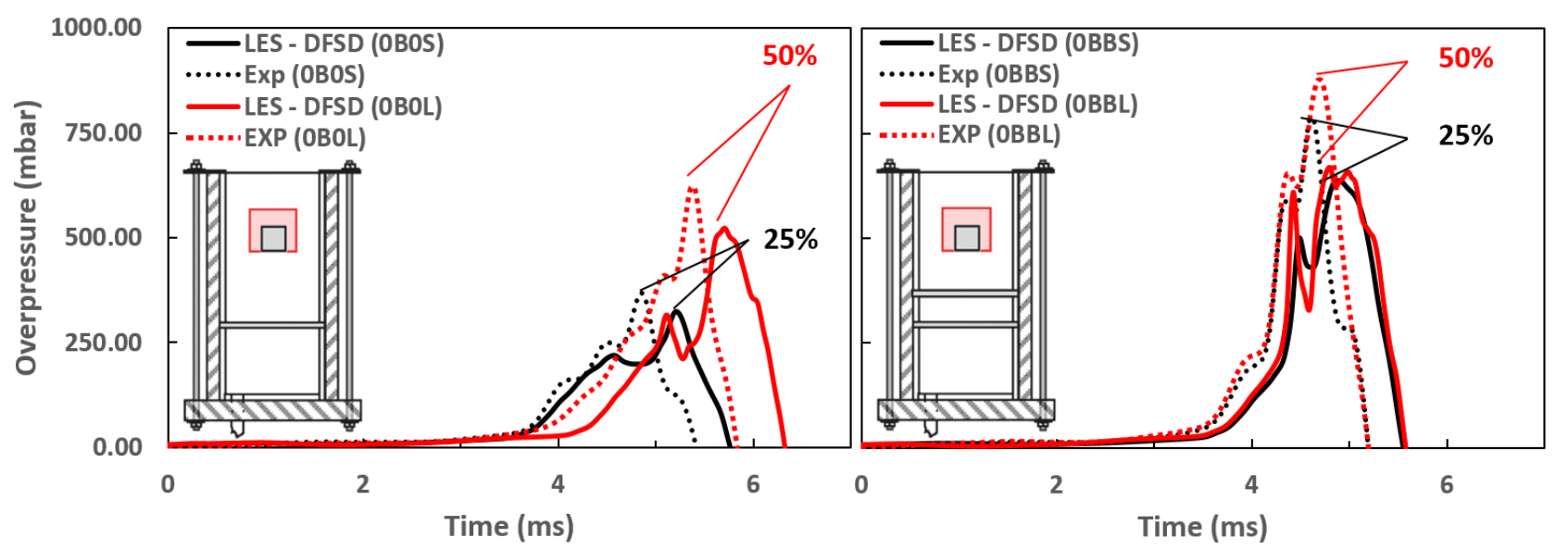

(a) Comparison between overpressure-time

(b) Comparison between overpressure-time traces for configurations $0 \mathrm{~B} 0 \mathrm{~S}$ and $\mathrm{OB} 0 \mathrm{~L}$. traces for configurations $\mathrm{OBBS}$ and $\mathrm{OBBL}$.
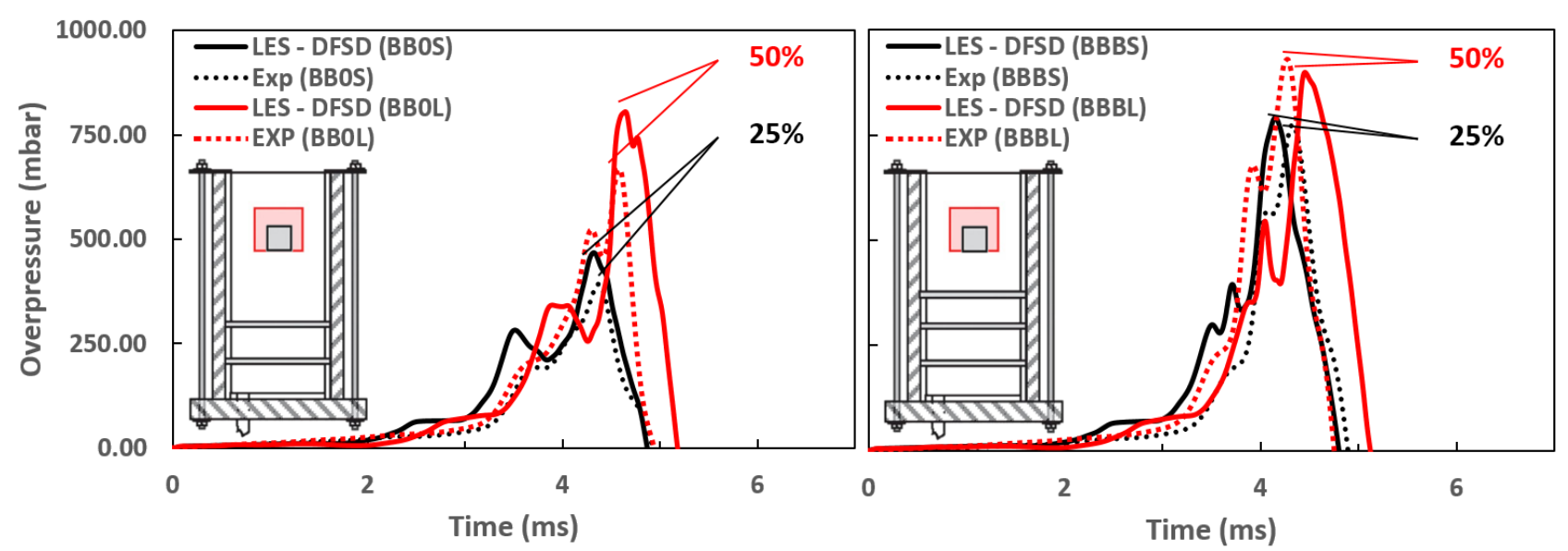

(c) Comparison between overpressure-time traces for configurations BBOS and BBOL.

(d) Comparison between overpressure-time traces for configurations BBBS and BBBL.

Fig. 5 - A comparison between overpressure-time traces using the smaller and larger ABR. 


\section{Effect of increased area blockage ratio}

Increasing the area blockage ratio impacts the flow path and subsequently impacts the flame structure. When comparing results for the same configuration using a different $A B R$, the flow initially follows an identical path as it propagates through the baffles. The most significant difference when using an increased ABR is that there is less area available for the flow to propagate past the obstruction meaning that there is a temporarily reduced flame speed as the spreading flame interacts with the solid obstacle. The flow then recirculates around the edges of the obstacle, allowing the consumption in the recirculating wake of unburned flow behind the obstacle. This wake is considerably larger when the ABR is approximately doubled resulting in an increased rate of pressure rise and a considerably higher peak combustion overpressure. Fig. 5 also helps identify that using the larger ABR increases the peak overpressure although it delays the time at which it occurs. This is particularly clear in Fig. $5 \mathrm{a}$, where the peak overpressure is delayed by $0.6 \mathrm{~ms}$ and increases by 200 mbar. Using an additional baffle decreases the time delay due to more of the mixture being burnt in less time due to the increased levels of turbulence in the chamber. This is shown in Fig. $5 \mathrm{c}$ where the peak overpressure occurs $0.3 \mathrm{~ms}$ later and increases by 340 mbar using the larger ABR. Fig. $5 \mathrm{~d}$ has the same delay of $0.3 \mathrm{~ms}$ with the overpressure increasing by approximately $100 \mathrm{mbar}$. The rate of pressure rise also increases when a larger $\mathrm{ABR}$ is utilised. Configuration OBOS produces a peak rate of pressure rise at $4.4 \mathrm{~ms}$ of $78 \mathrm{MPa} / \mathrm{s}$ whereas configuration OBOL produces peak dp/dt of $176.79 \mathrm{MPa} / \mathrm{s}$ at $5.97 \mathrm{~ms}$. The rise in overpressure using the larger obstacle is likely to be attributed to the interaction of the of the flame front with the larger recirculating wake of flow which is created behind the solid obstacle. Fig. 6 and Fig. 7 show images of hydrogen/air flames propagating past one baffle and a solid obstruction. The lack of detail in Fig. 7a when compared to Fig. $6 a$ is due to experimental limitations mentioned earlier. Images of the reaction zone are compared to results of the progress variable $\tilde{c}$ extracted from LES. The expanding flame forces the unburned mixture to go through the baffle which generates turbulent eddies. The initially laminar flame follows the path of the unburnt mixture through the baffle resulting in wrinkling of the flame front. As the flame passes through the baffle it separates into four different channels as a result of the baffle strips. These then reconnect due to the flame's lateral spread through the chamber, consuming the unburned mixture as shown at $4.8 \mathrm{~ms}$ in Fig. $7 \mathrm{~b}$. The flame then takes the path of least resistance to the side of the obstacle. As the flow propagates past the solid obstruction a wake of recirculating flow is generated behind it. The flow guides the flame to the unburned mixture in the wake. Comparing Fig. $6 \mathrm{~b}$ and $7 \mathrm{~b}$ shows the difference in the size of the wake due to the increased ABR and the increased distance that the flame covers before it reconnects behind the obstacle. Also, in Fig. $7 \mathrm{~b}$ at $5.6 \mathrm{~ms}$ there is still an unburned portion of the flow behind the large obstacle. The symmetrical nature of the flame throughout combustion phases conveys the homogenous nature of the mixture. The burned mixture then propagates out of the open end (vent) at the top of the chamber. Both Fig. 6 and 7 show the ability of the numerical model to reproduce the flame structure and transient flame speeds to a relatively high degree of accuracy for the small and large ABR. The numerical 
images show a well predicted flame structure and the interaction of the flame with the baffle and obstacles.

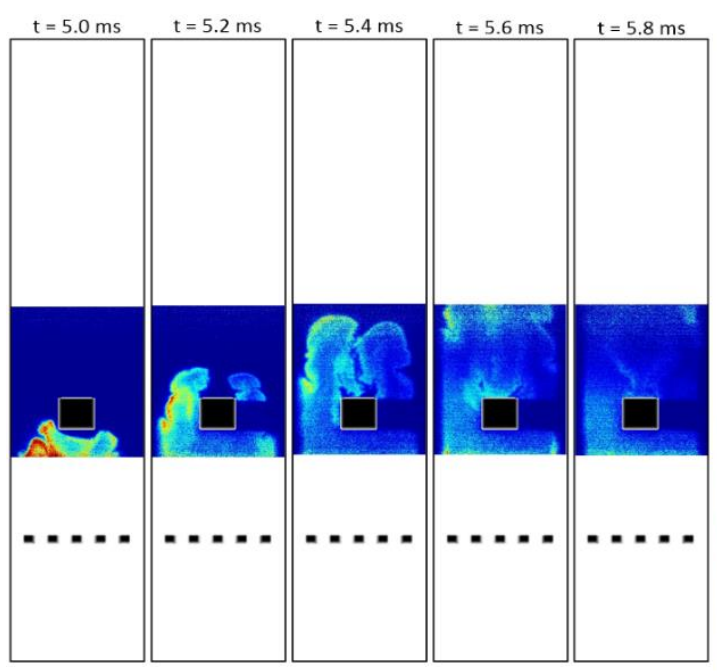

(a)

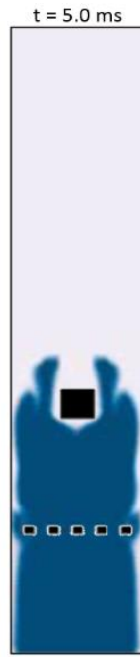

Fig. 6 - Flame s

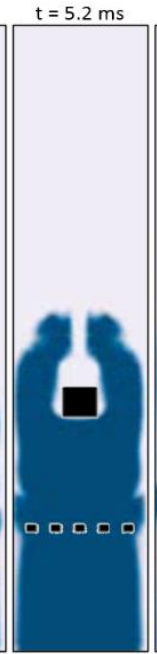

(b)

\section{numerical results for configuration OBOS.}

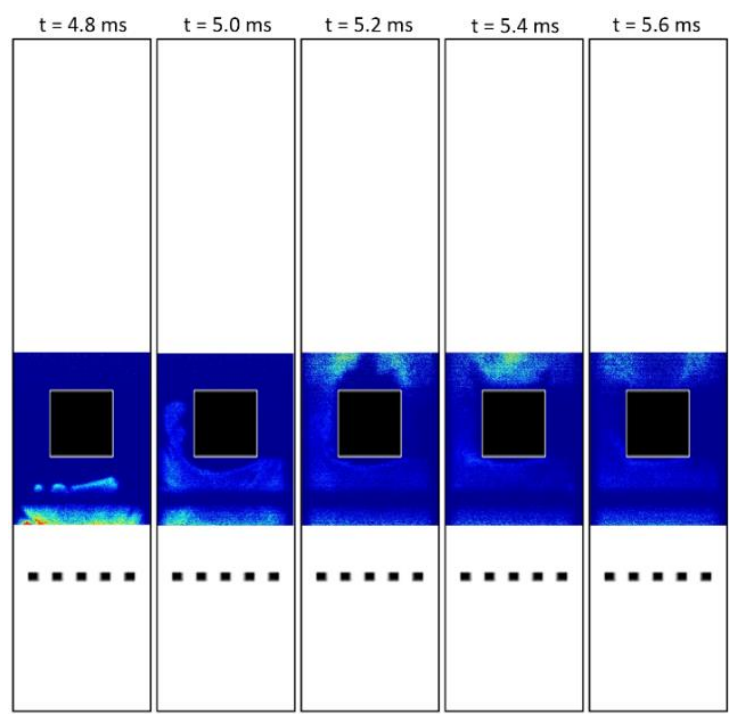

(a)
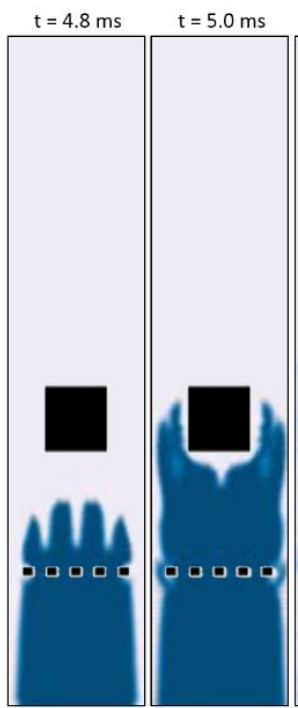

(b)

Fig. 7 - Flame structure comparison between (a) LIF - OH images and (b) numerical results for configuration $0 \mathrm{~B} 0 \mathrm{~L}$.

\section{Comparison with LPG}

A stoichiometric LPG/air mixture $(\Phi=1.0)$ behaves significantly differently when compared to a lean hydrogen/air mixture $(\Phi=0.7)$. A comparison is made between both fuels using three baffles with a small (BBBS) and large ABR (BBBL). The LPG used has a composition of $95 \% \mathrm{C}_{3} \mathrm{H}_{8}, 4 \% \mathrm{C}_{4} \mathrm{H}_{10}$ and $1 \%$ of other hydrocarbons by volume. The flame thickness is set to $37 \mathrm{~mm}$ with a laminar burning velocity of 0.39 $\mathrm{m} / \mathrm{s}$ [59]. Fig. 8 and Fig. 9 compare the overpressure time traces between LPG and hydrogen flames. Using the lean hydrogen mixture, configuration BBBL a peak 
combustion overpressure of $898 \mathrm{mbar}$ at $4.46 \mathrm{~ms}$ is seen whereas the stoichiometric LPG mixture only produced 107 mbar at 10.38 ms. Similarly, when using a smaller ABR, LPG using configuration BBBS produces a peak overpressure of 99 mbar at $10.52 \mathrm{~ms}$, while $\mathrm{H}_{2}$ produced a peak overpressure of $789 \mathrm{mbar}$ at $4.15 \mathrm{~ms}$. Increasing the ABR of the solid obstacle increased the peak overpressure by $14 \%$ for $\mathrm{H}_{2}$ when compared to LPG which increased by $8 \%$. The overpressure histories show that LPG with a higher equivalence ratio produces approximately $10 \%$ of the overpressure when compared to hydrogen. It also takes more than double the amount of time to do so. Further, the rate at which pressure rises for LPG is increased from $8.06 \mathrm{MPa} / \mathrm{s}$ to $13.85 \mathrm{MPa} / \mathrm{s}$ whereas the hydrogen mixture increases from $300.46 \mathrm{MPa} / \mathrm{s}$ to $349.56 \mathrm{MPa} / \mathrm{s}$. This highlights the sensitivity of the lean hydrogen mixture to turbulence as well as the ABR when compared to propane. Note that the LES model can reproduce the overpressure-time traces for both fuels to a high degree of accuracy in a high turbulence environment.

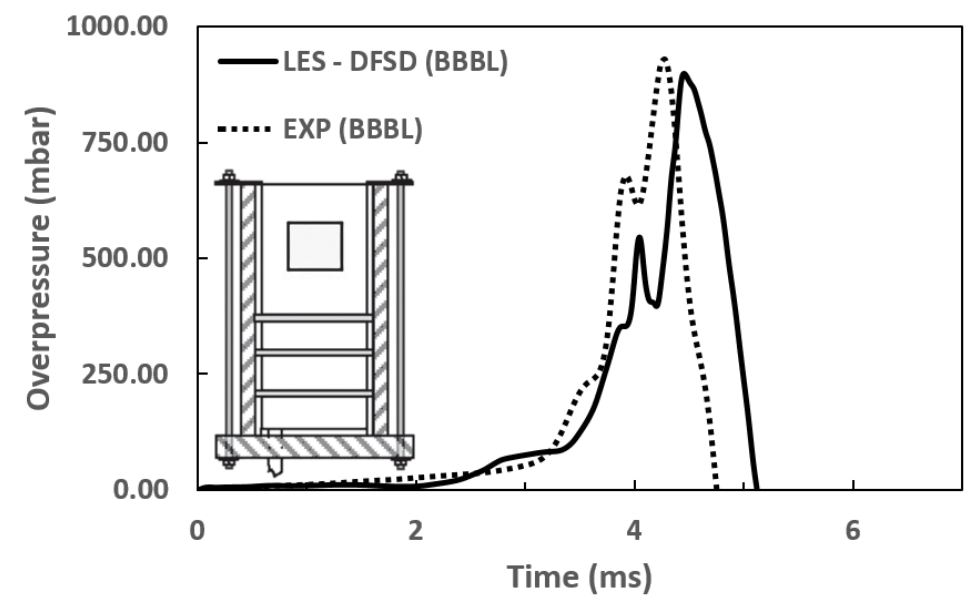

(a)

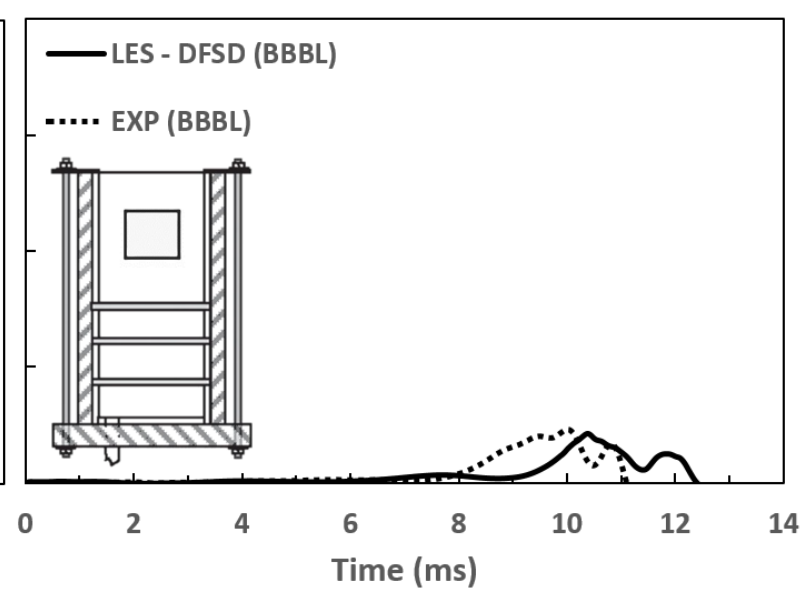

(b)

Fig. 8 - Overpressure-time traces for $\mathrm{H}_{2}$ (a) and LPG (b) using configuration BBBL.

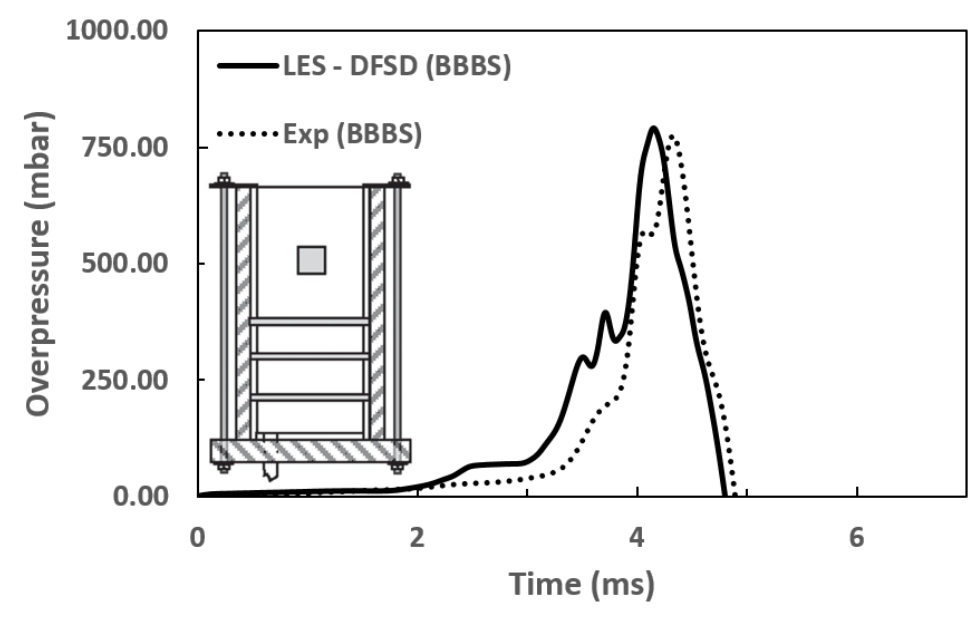

(a)

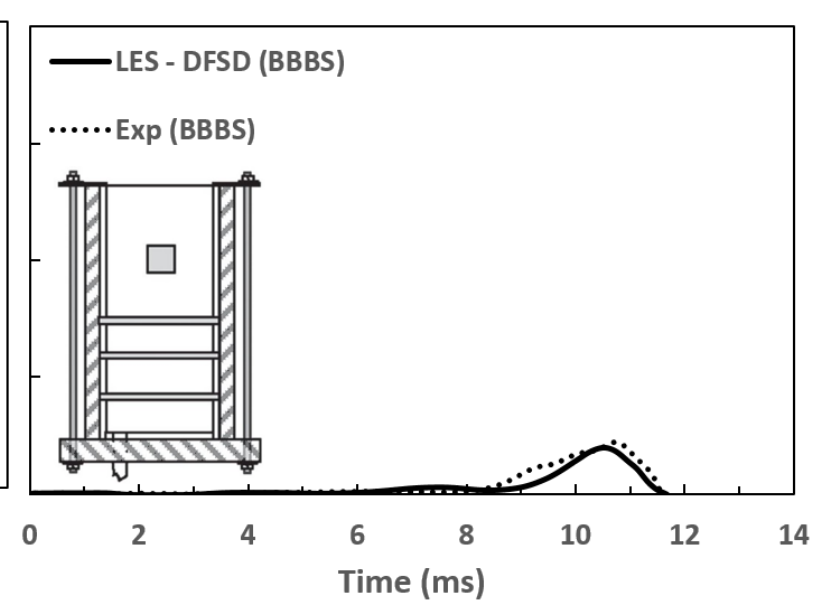

(b)

Fig. 9 - Overpressure-time traces for $\mathrm{H}_{2}(\mathrm{a})$ and LPG (b) using configuration BBBS. 


\section{Flame position and speed}

Flame position-time traces are shown in Fig. 10a for the large ABR and Fig. 10b for the small ABR with a maximum flame position of $250 \mathrm{~mm}$. Experimental data is limited for the large ABR as mentioned earlier. The flame transient speeds are shown in Fig.11. Comparing Fig. 10a and 10b shows that the flame generally requires more time in order to propagate past the large solid obstacle. Further, increasing the $A B R$ also means that the flame requires additional time when in interacts with and subsequently propagates past the solid obstacle after which the increased turbulence intensity results in the jetting of the flame at higher speeds.

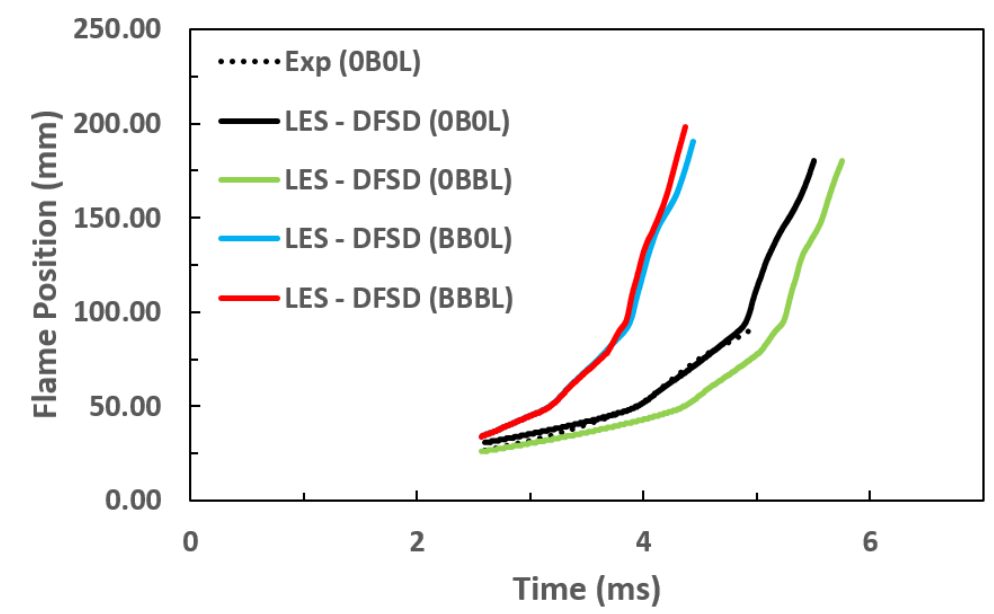

(a)

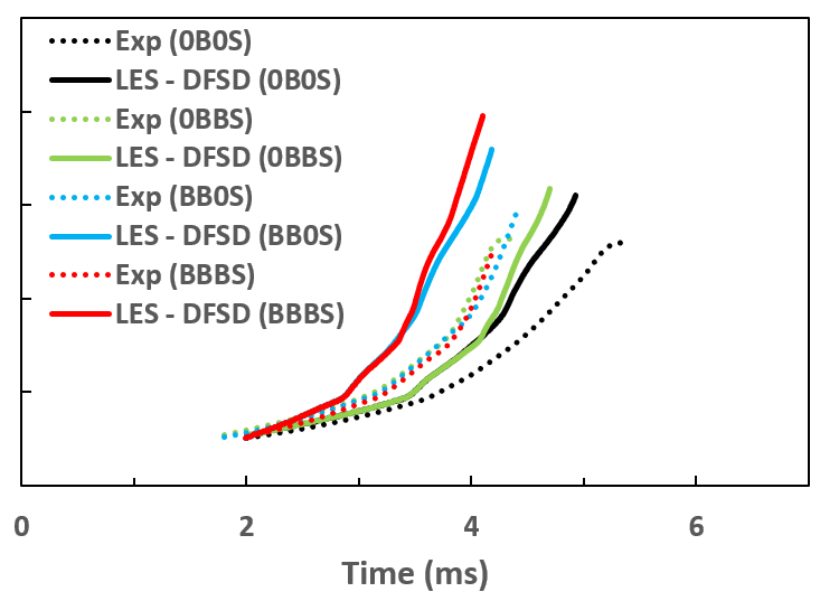

(b)

Fig. 10 - Flame position-time traces for (a) large and (b) small ABR.

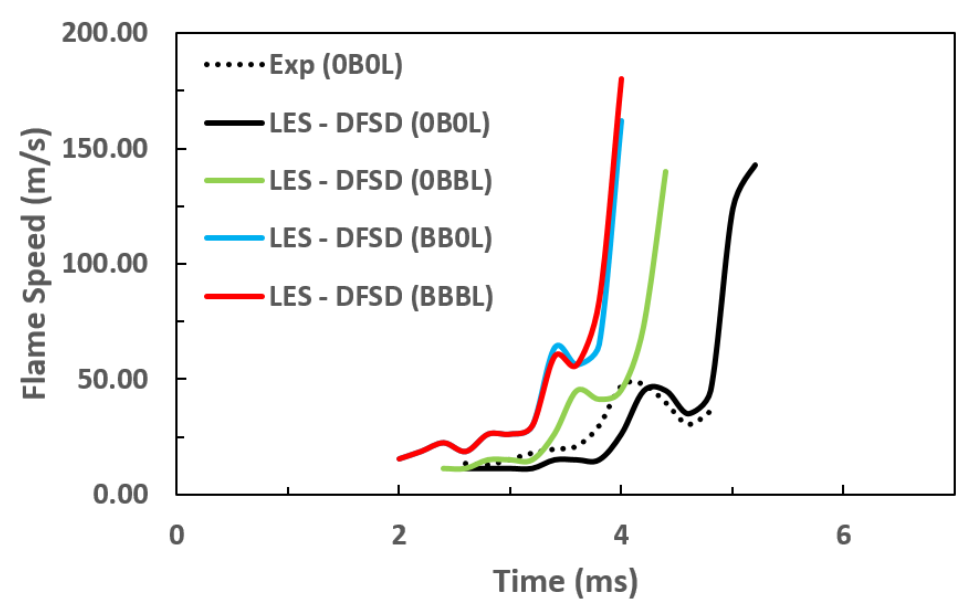

(a)

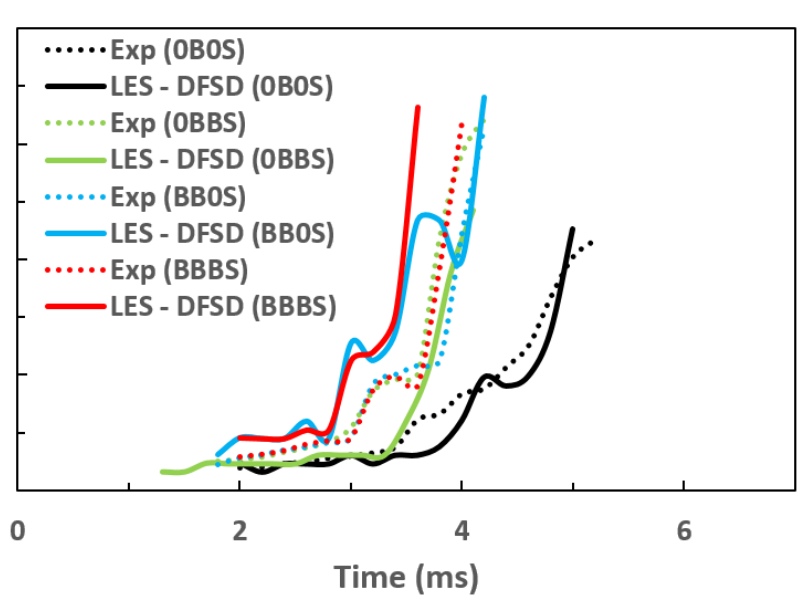

(b)

Fig. 11 - Flame speed-time traces for (a) large and (b) small ABR.

Configurations $\mathrm{OBOL}$ and $\mathrm{OB} 0 \mathrm{~S}$ can be used as to demonstrate this as they are both validated against experimental data. At $4.8 \mathrm{~ms}$, configuration OBOS has a flame speed of $68.45 \mathrm{~m} / \mathrm{s}$ whereas configuration OBOL has a flame speed of $45 \mathrm{~m} / \mathrm{s}$. However, at $5.0 \mathrm{~ms}$, configuration OBOS reaches a maximum flame speed of 112.94 $\mathrm{m} / \mathrm{s}$ while the increased $A B R$ results in a flame speed of $124.23 \mathrm{~m} / \mathrm{s}$ at $5.0 \mathrm{~ms}$, which then increases to $143.06 \mathrm{~m} / \mathrm{s}$ at $5.20 \mathrm{~ms}$. Adding further baffles also promotes the generation of turbulence and subsequently increases combustion in the chamber 
resulting in a faster propagating flame that departs the chamber in less time as shown in Fig. 10 and 11. This is conveyed when looking at figures for both the ABRs as increasing the number of baffles shifts the traces to occur in a reduced timeframe at higher flame speeds.

\section{Conclusions}

Research presented in this paper studied large eddy simulations using the dynamic flame surface density model to numerically investigate hydrogen combustion in a laboratory-scale combustion chamber. Four different baffle configurations were utilised to compare study the effects of a small ABR and a large ABR. A comparison with LPG/air $(\Phi=1.0)$ confirms the sensitivity of a hydrogen/air $(\Phi=0.7)$ mixture which produced a magnitude greater peak overpressure in under half the time duration following ignition. Based on the numerical results and analysis presented in this paper, the following conclusions are drawn:

- Hydrogen flames are quasi-laminar until they interact and propagate through baffles inducing turbulence. Including successive baffles will increase the turbulence intensity and create a complex wrinkled flame.

- Increasing the number of baffles and the ABR will raise the peak magnitude of overpressure and the peak rate at which pressure rises.

- The peak overpressure magnitude and timing are affected by the ABR and the relative distance of the baffles to the ignition source.

- The ABR of the obstacle impacts the flame structure as a result of the size of the flow generated wake behind the obstacle.

- The ABR has more of an effect on peak overpressure timing in configurations with less baffles and less of an effect on the magnitude with configurations employing more baffles.

- $\quad$ The LES - DFSD numerical approach is found to produce results with a high degree of accuracy when compared with experimental data.

REFEREN CES

[1] Møller KT, Jensen TR, Akiba E, Li H wen. Hydrogen - A sustainable energy carrier. Prog Nat Sci Mater Int 2017;27:34-40.

https://doi.org/10.1016/j.pnsc.2016.12.014.

[2] Marbán G, Valdés-Solís T. Towards the hydrogen economy? Int J Hydrogen Energy 2007;32:1625-37. https://doi.org/10.1016/j.ijhydene.2006.12.017.

[3] Veziroglu A, MacArio R. Fuel cell vehicles: state of the art with economic and environmental concerns. Int J Hydrogen Energy 2011;36:25-43. https://doi.org/10.1016/j.ijhydene.2010.08.145.

[4] Hasegawa T, Imanishi H, Nada M, Ikogi Y. Development of the fuel cell system in the Mirai FCV. SAE Tech Pap 2016;1185. https://doi.org/10.4271/2016-011185.

[5] Lipman TE, Elke M, Lidicker J. Hydrogen fuel cell electric vehicle performance and user-response assessment: Results of an extended driver study. Int $\mathrm{J}$ Hydrogen Energy 2018;43:12442-54.

[6] White CM, Steeper RR, Lutz AE. The hydrogen-fueled internal combustion 
engine: a technical review. Int J Hydrogen Energy 2006;31:1292-305.

[7] Dodds PE, Staffell I, Hawkes AD, Li F, Grünewald P, McDowall W, et al. Hydrogen and fuel cell technologies for heating: A review. Int J Hydrogen Energy 2015;40:2065-83.

[8] Lee Y, Kim J, Kim J, Kim EJ, Kim YG, Moon I. Development of a web-based $3 \mathrm{D}$ virtual reality program for hydrogen station. Int J Hydrogen Energy 2010;35:2112-8.

[9] Kim E, Park J, Cho JH, Moon I. Simulation of hydrogen leak and explosion for the safety design of hydrogen fueling station in Korea. Int $\mathrm{J}$ Hydrogen Energy 2013;38:1737-43.

[10] Angers B, Hourri A, Bernard P, Demaël E, Ruban S, Jallis S. Modeling of hydrogen explosion on a pressure swing adsorption facility. Int $\mathrm{J}$ Hydrogen Energy 2014;39:6210-21.

[11] Kikukawa S, Mitsuhashi H, Miyake A. Risk assessment for liquid hydrogen fueling stations. Int J Hydrogen Energy 2009;34:1135-41.

[12] Bjerketvedt D, Bakke JR, Wingerden K Van. Gas explosion handbook. J Hazard Mater 1997;52:1-150.

[13] HX, Wang Q, He X, Sun J, Shen X. Experimental study on the behaviors and shape changes of premixed hydrogen-air flames propagating in horizontal duct. Int J Hydrogen Energy 2011;36:6325-36.

[14] H X, Shen X, Sun J. Experimental study and three-dimensional simulation of premixed hydrogen/air flame propagation in a closed duct. Int $\mathrm{J}$ Hydrogen Energy 2012;37:11466-73.

[15] Rocourt X, Awamat S, Sochet I, Jallis S. Vented hydrogen-air deflagration in a small enclosed volume. Int J Hydrogen Energy 2014;39:20462-6.

[16] Masri AR, Al-Harbi AA, Meares S, Ibrahim SS. A comparative study of turbulent premixed flames propagating past repeated obstacles. Ind Eng Chem Res 2011;51:7690-703. https://doi.org/10.1021/ie201928g.

[17] Al-Harbi AA, Masri AR, Ibrahim SS. Turbulent premixed flames of CNG, LPG , and $\mathrm{H} 2$ propagating past repeated obstacles. Exp Therm Fluid Sci 2014;56:28. https://doi.org/10.1016/j.expthermflusci.2013.11.012.

[18] Yanez J, Kuznetsov M, Souto-Iglesias A. An analysis of the hydrogen explosion in the Fukushima-Daiichi accident. Int $\mathrm{J}$ Hydrogen Energy 2015;40:8261-80. https://doi.org/10.1016/j.ijhydene.2015.03.154.

[19] Barletta WA, Stoop J, O'Hara C, Bailiff I, Hermanspahn N. 5 years after Fukushima - insights from current research. Elsevier 2016. https://www.elsevier.com/connect/5-years-after-fukushima-insights-fromcurrent-research (accessed November 29, 2019).

[20] Patel SNDH, Jarvis S, Ibrahim SS, Hargrave GK. An experimental and numerical investigation of premixed flame deflagration in a semiconfined explosion chamber. Proc Combust Inst 2002;29:1849-54. https://doi.org/10.1016/S1540-7489(02)80224-3. 
[21] Ibrahim SS, Gubba SR, Masri AR, Malalasekera W. Calculations of explosion deflagrating flames using a dynamic flame surface density model. J Loss Prev Process Ind 2009;22:258-64. https://doi.org/10.1016/j.jp.2008.05.006.

[22] Gubba SR, Ibrahim SS, Malalasekera W, Masri AR. An assessment of large eddy simulations of premixed flames propagating past repeated obstacles. Combust Theory Model 2009;13:513-40. https://doi.org/10.1080/13647830902928532.

[23] Gubba SR, Ibrahim SS, Malalasekera W. LES study of influence of obstacles on turbulent premixed flames in a small scale vented chamber. 6th Mediterr Combust Symp 2009.

[24] Gubba SR, Ibrahim SS, Malalasekera W, Masri AR. Measurements and LES calculations of turbulent premixed flame propagation past repeated obstacles. Combust Flame 2011;158:2465-81. https://doi.org/10.1016/j.combustflame.2011.05.008.

[25] Gubba SR. Development of a dynamic LES model for premixed turbulent flames. Ph.D. thesis. Loughborough University, 2009.

[26] Bauwens CR, Chaffee J, Dorofeev SB. Vented explosion overpressures from combustion of hydrogen and hydrocarbon mixtures. Int J Hydrogen Energy 2011;36:2329-36. https://doi.org/10.1016/j.ijhydene.2010.04.005.

[27] Guo J, Li Q, Chen D, Hu K, Shao K, Guo C, et al. Effect of burst pressure on vented hydrogen-air explosion in a cylindrical vessel. Int J Hydrogen Energy 2015;40:6478-86. https://doi.org/10.1016/j.jhydene.2015.03.059.

[28] Guo J, Sun X, Rui S, Cao Y, Hu K, Wang C. Effect of ignition position on vented hydrogen-air explosions. Int J Hydrogen Energy 2015;40:15780-8. https://doi.org/10.1016/j.ijhydene.2015.09.038.

[29] Rocourt X, Sochet I, Pellegrinelli B. Small-scale flame acceleration and application of medium and large-scale flame speed correlations. Int $\mathrm{J}$ Hydrogen Energy 2017;42:1327-36.

https://doi.org/10.1016/j.ijhydene.2016.10.042.

[30] Popat NR, Catlin CA, Arntzen BJ, Lindstedt RP, Hjertager BH, Solberg T, et al. Investigations to improve and assess the accuracy of computational fluid dynamic based explosion models. J Hazard Mater 1996;45:1-25. https://doi.org/10.1016/0304-3894(95)00042-9.

[31] Middha P, Hansen OR, Storvik IE. Validation of CFD-model for hydrogen dispersion. J Loss Prev Process Ind 2009;22:1034-8. https://doi.org/10.1016/j.jlp.2009.07.020.

[32] Middha P. Development, use, and validation of the CFD tool FLACS for hydrogen safety studies. Ph.D. thesis. University of Bergen, 2010.

[33] Matsuura K, Kanayama H, Tsukikawa H, Inoue M. Numerical simulation of leaking hydrogen dispersion behavior in a partially open space. Int $J$ Hydrogen Energy 2008;33:240-7. https://doi.org/10.1016/j.ijhydene.2007.08.028.

[34] Vyazmina E, Jallais S. Validation and recommendations for FLACS CFD and engineering approaches to model hydrogen vented explosions: effects of 
concentration, obstruction vent area and ignition position. Int $\mathrm{J}$ Hydrogen Energy 2016;41:15101-9. https://doi.org/10.1016/j.ijhydene.2016.05.189.

[35] Catlin CA, Fairweather M, Ibrahim SS. Predictions of turbulent, premixed flame propagation in explosion tubes. Combust Flame 1995;102:115-28.

[36] Beard T, Bragin M, Malalasekera W, Ibrahim SS. Numerical simulation of hydrogen discharge in a partially enclosed space. Phys Procedia 2015;66:153-6. https://doi.org/10.1016/j.egypro.2015.02.083.

[37] Abdel-Raheem MA, Ibrahim SS, Malalasekera W, Masri AR. Large eddy simulation of hydrogen-air premixed flames in a small scale combustion chamber. Int J Hydrogen Energy 2015;40:3098-109. https://doi.org/10.1016/j.ijhydene.2014.12.042.

[38] Abdel-Raheem MA. Numerical study of the characteristics of CNG, LPG and hydrogen turbulent premixed flames. Ph.D Thesis. Loughborough University, 2015.

[39] Li R, Malalasekera W, Ibrahim S. Numerical study of vented hydrogen explosions in a small scale obstructed chamber. Int $\mathrm{J}$ Hydrogen Energy 2018;43:16667-83. https://doi.org/10.1016/j.ijhydene.2018.07.078.

[40] Versteeg HK, Malalasekera W. An introduction to computational fluid dynamics - the finite volume method. Second Ed. Pearson; 2007.

[41] Marangon A, Schiavetti M, Carcassi M, Pittiglio P, Bragatto P, Castellano A. Turbulent hydrogen deflagration induced by ostacles in real confined environment. Int J Hydrogen Energy 2009;34:4669-74. https://doi.org/10.1016/j.ijhydene.2008.07.053.

[42] Baraldi D, Kotchourko A, Lelyakin A, Yanez J, Gavrikov A, Efimenko A, et al. An inter-comparison exercise on CFD model capabilities to simulate hydrogen deflagrations with pressure relief vents. Int J Hydrogen Energy 2010;35:12381-90. https://doi.org/10.1016/j.ijhydene.2010.08.106.

[43] Baraldi D, Melideo D, Kotchourko A, Ren K, Yanez J, Jedicke O, et al. Development of a model evaluation protocol for CFD analysis of hydrogen safety issues the SUSANA project. Int J Hydrogen Energy 2017;42:7633-43. https://doi.org/10.1016/j.ijhydene.2016.05.212.

[44] Masri AR, Ibrahim SS, Cadwallader BJ. Measurements and large eddy simulation of propagating premixed flames. Exp Therm Fluid Sci 2006;30:687702. https://doi.org/10.1016/j.expthermflusci.2006.01.008.

[45] Gubba SR, Ibrahim SS, Malalasekera WMG. A dynamic SGS model for LES of turbulent premixed flames. Int. Symp. Adv. Comput. Heat Transf., 2008. https://doi.org/10.1615/ichmt.2008.cht.840.

[46] Gubba SR, Ibrahim SS, Malalasekera W. A parametric study on large eddy simulations of turbulent premixed flames. Proc. Eighth Asia Pacific Conf. Combust., 2010.

[47] Gubba SR, Ibrahim SS, Malalasekera W, Masri AR. LES modeling of premixed deflagrating flames in a small-scale vented explosion chamber with a series of solid obstructions. Combust Sci Technol 2008;180:1936-55. 
https://doi.org/10.1080/00102200802261852.

[48] Gubba SR, Ibrahim SS, Masri AR. LES modelling of propagating turbulent premixed flames using a dynamic flame surface density model. 2nd ECCOMAS Themat. Conf. Comput. Combust., 2007.

[49] Abdel-Raheem MA, Ibrahim SS, Malalasekera W. Numerical experiments of hydrogen-air premixed flames. Int J Res Eng Sci 2014;2:48-55.

[50] Li R, Malalasekera W, Ibrahim SS. Numerical investigation of early flame propagation in vented explosions. Tenth Mediterr Combust Symp 2017.

[51] Li R, Malalasekera W, Ibrahim S. LES-DFSD modelling of turbulent premixed flames past repeated obstacles. Proc. 3rd World Congr. Momentum, Heat Mass Transf., 2018, p. 1-8. https://doi.org/10.11159/csp18.108.

[52] Li R, Malalasekera W, Ibrahim SS, Liu B. On the mechanism of pressure rise in vented explosions: A numerical study. IChemE 2018;117:551-64. https://doi.org/10.1016/j.psep.2018.05.026.

[53] Di Sarli V, Di Benedetto A, Russo G. Using large eddy simulation for understanding vented gas explosions in the presence of obstacles. J Hazard Mater J 2009;169:435-42. https://doi.org/10.1016/j.jhazmat.2009.03.115.

[54] Makarov D, Molkov V, Gostintsev YU. Comparison between RNG and fractal combustion models for LES of unconfined explosions. Combust Sci Technol 2007;179:401-16. https://doi.org/10.1080/00102200600835626.

[55] Molkov V, Verbecke F, Makarov D. LES of hydrogen-air deflagrations in a 78.5-m tunnel. Combust Sci Technol 2008;180:796-808. https://doi.org/10.1080/00102200801893994.

[56] Boger M, Veynante D, Boughanem H, Trouve A. Direct numerical simulation analysis of flame surface density concept for large eddy simulation of turbulent premixed combustion. Twenty-Seventh Symp. Combust. Combust. Inst., 1998, p. 917-25.

[57] Ma T, Stein OT, Chakraborty N, Kempf AM. A posteriori testing of algebraic flame surface density models for LES. Combust Theory Model 2013;17:43182. https://doi.org/10.1080/13647830.2013.779388.

[58] Hawkes ER, Cant RS. A flame surface density approach to large-eddy simulation of premixed turbulent combustion. Proc. Combust. Inst., vol. 28, 2000, p. 51-8.

[59] Wang G, Boileau M, Veynante D, Truffin K. Large eddy simulation of a growing turbulent premixed flame kernel using a dynamic flame surface density model. Combust Flame 2012;159:2742-54.

https://doi.org/10.1016/j.combustflame.2012.02.018.

[60] Al-Harbi AA. Turbulent premixed flames propagating past repeated obstacles. Ph.D. Thesis. The Univeristy of Sydney, 2013.

[61] Boger M. Modélisation de sous-maille pour la simulation aux grandes échelles de la combustion turbulente prémélangée. Ph.D. thesis. Ecole Centrale Paris, 2000. 
[62] Aung KT, Hassan MI, Faeth GM. Flame stretch interactions of laminar premixed hydrogen/air flames at normal temperature and pressure. Combust Flame 1997;109:1-24.

[63] Vermorel O, Quillatre P, Poinsot T. LES of explosions in venting chamber: a test case for premixed turbulent combustion models. Combust Flame 2017;183:207-23.

[64] Kirkpatrick MP. A large eddy simulation code for industrial and environmental flows. Ph.D. thesis. The University of Sydney, 2002.

[65] Werner H, Wengle H. Large-Eddy Simulation of Turbulent Flow Over and Around a Cube in a Plate Channel. In: Durst F, Friedrich R, Launder B., Schmidt F., Schumann U, Whitelaw JH, editors. Turbul. Shear Flows 8, Berlin, Heidelberg: Springer; 1993.

[66] Na'inna AM, Phylaktou HN, Andrews GE. The acceleration of flames in tube explosions with two obstacles as a function of the obstacle separation distance. J Loss Prev Process Ind 2013;26:1597-603.

https://doi.org/10.1016/j.jp.2013.08.003. 